\title{
The 'Rurban' Society in India: new facets of Urbanism and its Challenges
}

\author{
Sumana Chatterjee \\ (Urban Management, Centre for Good Governance, Hyderabad, India)
}

\begin{abstract}
The paper challenges the traditional concept of evolution of urban areas wherein, the process of urbanization witnesses economic transformation along with associated socio-cultural changes. India in the last decade has witnessed a huge increase in growth of such non-farm based economy driven urban areas where, the socio-cultural aspects are still rural. These urban areas, evolving from large villages, are defined as 'census towns' by the Census of India, and are widely referred to as 'rurban' areas in the domain of research. The new aspects of urbanism that these rurban areas portray, completely washes away the stereotyped perception about an urban society in India. The rurban society not only brings in new faces to urbanism, but upheld the challenges towards their acknowledgement and inclusion in the existing urban society. Through case illustration of few census towns, the paper attempts to apathetically understand the difference rurban society makes to themselves and to urban societies, when they grow only economically sans basic necessities and sociocultural amenities. The paper concludes to stir a thought among the readers, and expand scope for further research on, nurturing and developing the rurban society in India with necessary policy attentions.
\end{abstract}

Keywords: economy, development policies, rurban, society, urbanism

\section{Introduction}

The ongoing process of urbanization and urban growth in India, driven by rapidly evolving non-farm based economy vis-à-vis. stagnation in socio-cultural transformation, has opened up new dimensions to perceive urbanism in the rurban society. The census towns, addressed to as 'rurban' areas in the paper, though are defined by the Census of India as 'urban' but are governed by Rural Local Bodies (Gram Panchayats), and in very few cases, by Nagar Panchayats. The decade 2001-11 has witnessed growth of 3894 such census towns as against 1362 in 1991-2001, while statutory towns have only increased marginally from 3799 to 4041 in number in the same decades [1]. Quite a few scholarly literatures have foreseen this remarkable increase of 2774 new census towns [2], as a major challenge in urban planning. Some other research articles have focussed on state specific growth factors, stories of evolution and need for attention of policy makers. The research area that has been left unaddressed is how the society in such urban areas is evolving and adjusting to the rapid rural urban dynamics.

The paper contributes in this area of research gap to mainstream social development policies in urban planning policies for rurban areas, as an utmost necessary action with the purpose to, achieve overall inclusive development of urban areas in India. At present, neither the urban nor the rural plan policies, acknowledge the existence and promote development of rurban areas; nor the social development policies target betterment of the rurban society. Though the Provision of Urban Amenities in Rural Areas (PURA) Scheme, has been proposed to be revamped as the new PURA/ PURA2.0 with the purpose of infrastructure provision and creation of growth poles for development in the rurban areas, the focus is only limited to physical infrastructure development. What goes missing is the social and community infrastructure development part, like access to primary, secondary schools, colleges, health centres, emergency services, community halls, banks, etc. Physical infrastructure can definitely bring development to a place, but it must be accompanied by social infrastructure to build on the society and its progress. No studies have been actually carried out in understanding the evolving rurban society and new urbanism in rurban areas, and the challenges that they may pose in near future. The present study upholds some new facets of urbanism in rurban society to carry forward their development concerns in the eyes of social and urban policy planners.

Sound rationale behind the study is the importance of rurban areas in itself, and hence the need for acknowledging, nurturing and developing the rurban society. Census towns have contributed to 29.5 per cent [3] of urban growth in India between 2011-11. Besides, importance of census towns is also realized in terms of potential economic spaces with changing livelihood options, possible sources of revenue generation at local level, rising service sector contribution to the economy, future growth engines of cities, target centres for investment in manufacturing and construction, rising consumer economy and new evolving electoral hubs. Considering the varied potential of growth in rurban areas, the rurban society demands its development to be at par with other urban societies. 


\section{Urban Society and Urbanism}

The conventional research works on issues and characteristics of urban society and urban life, has been based on traditional concepts and definitions of urban areas [4]. The notion of 'urban society' to an individual's mind, provides glimpses of heterogeneous population, polarized and unequal social classes, spatial segregation of residential community, limited neighbourhood networking, secluded class of urban poor, etc., as against a simple homogenous society in rural areas. Similarly, 'urbanism', the way of life in urban areas vis-à-vis in rural areas is markedly different in culture like dress habits, recreational options, consumption pattern, social aspects like interaction, competition, sense of security, status awareness, etc. The binding factor that sustains urbanism in an urban society is the adequate provision of socio-cultural facilities and amenities.

Now, with this conventional understanding about society and way of life in urban areas, one will actually find hard to relate the new dimensions of urbanism in the evolving rurban society in India. In fact, the very phenomenon of urbanization defined as, the process of transformation from a predominantly rural economy, society and culture to predominantly urban, partially contradicts the actual phenomenon of urbanization in rurban areas wherein, the process of economic transformation is markedly rapid, but it is not accompanied by socio-cultural transformation. Provision of basic socio-cultural amenities, which is the basis for initiating an urban way of life, goes missing in these rurban areas leading to a stagnant society. The following section provides an insight to the characteristics of the evolving rurban space in India.

\section{The evolving Rurban space and its characteristics}

"Though the term urbanization brings to our mind the image of metropolis and mega cities, a larger picture of the process in India is actually captured by these 'rurban' areas, shifting contemporary research concerns from urbanization to the phenomenon of 'rurbanization' " [5]. Origin of new census towns in India can be attributed to reclassification of villages and out growths [3]. Growth of census towns in India varies largely across states; Kerala has the highest share (93\%) followed by West Bengal (66\%), while the lowest share has been observed for Chhattisgarh (4\%) and Madhya Pradesh (9\%) [3]. Studies show that the census towns have not necessarily grown around the metropolitan cities, but are widely spread with proximity and accessibility to small and medium towns in the country. The factor of spatial spread also shows a state-wide variation; only 25 per cent of the census towns in West Bengal have come up within urban agglomerations, while rest 75 per cent have emerged far away from the metropolitan dominance; in Tamil Nadu, they are mainly grown around urban agglomerations and IT hubs, while in Kerala, they have grown in rural-urban fringes, forming a 'desakota' kind of settlement.

The triggering factor for growth of census towns is directly related to their economic transformation characterized by increase in rural non-farm employment and shift of manufacturing activities away from metropolitan cores to small and medium towns [6]. Therefore the rurban space can be perceived as an emerging local network of market place, service trade centres, pool of construction and manufacturing labour source etc. interlinked with the larger city network system.

Though economy of census towns is mainly non-agricultural, they have not been given municipal status. Governed by Gram Panchayats, these towns are not able to maximize their own revenue base. Moreover, receipt of funds from rural development programmes are hardly utilized for development of census towns, but for other villages in the jurisdiction. In addition, the census towns lack urban service delivery mechanisms and provision of basic urban amenities due to the absence of municipal governance. Scholarly articles have largely raised concerns regarding lack of efficient governance, inadequate infrastructure facilities and basic services in census towns. Lack of unity among the local people in census towns for getting census recognition, possibility of misleading policies due to underestimation of urbanization, non-existence of reforms for census town development, lack of attention towards need of state specific policies, are other areas of serious concern in the rurban areas. Now, here comes in the need to look into the rurban society and its new urbanism dimensions because, urbanization process is organic and continuous in nature, but how the growing society perceives, adopts and makes the best living out of it, is what that matters.

\section{Perceiving new Urbanism: emerging facets of the Rurban society}

Understanding evolution of urban areas only in terms of growth and planning is not sufficient enough to achieve an inclusive development; one has to put oneself to the shoes of the evolving society, to imbibe their experiences and acknowledge their points of view of the ongoing rural-urban transformation. Through case illustration of few census towns in the state of West Bengal, the paper attempts to apathetically understand the difference rurban society makes to themselves and to urban societies, when they grow only economically sans basic necessities and socio-cultural amenities. 


\subsection{Case Studies}

Among all other states in India, the state of West Bengal has evidenced the maximum number of growth of census towns (780 in 2011 from 252 in 2001) as against only 127 statutory towns in 2011 [1]. A higher urbanization level than national average coupled with increasing urban growth and declining rural growth, indicate more and more conversion of large villages into census towns in the last decade. Statistics show that most of these newly added urban areas have remained as census towns for more than a decade and have still not been accorded with a municipal status. About 75 per cent of these census towns are located away from Urban Agglomerations [7], but all of them have strong rural-urban linkages through accessibility of highways and railways.

All the census towns are characterized by high incidence of mobility, both in terms of migration and commuting. The rurban space, is intricately woven with nearby towns and cities and with the Kolkata metropolis in terms of economic inter-linkages, but for most of them, the driving factors of growth are independent like, market forces, educational institutions, industries, place of historical importance, etc. Last decade development in most of these areas was towards betterment of physical infrastructure majorly roads, and towards massive conversion of 'kutcha' houses to 'pucca' ones. Such urban processes are coupled with sale of land at a two-fold or three-fold increased price rates. The towns experience a highly diversified non-farm economy from construction sector to manufacturing to retail trades, to other service-oriented trade and business; but lack basic socio-cultural amenities within accessible distance. These areas face every day issues like that in an urban area, but still give an image of a rural area. Given this backdrop, illustration of the experiences of rurban society in some of these census towns, as documented in TABLE1, opens up new dimensions of urbanism and challenges in India.

Table1. Facets of new Urbanism in the Census Towns of West Bengal, 2013

\begin{tabular}{|c|c|}
\hline $\begin{array}{l}\text { Evolving Rurban Society vis-à-vis perceived Urban } \\
\text { Society }\end{array}$ & $\begin{array}{c}\text { Images of Census Towns/Rurban Areas in West Bengal, } \\
\text { India }\end{array}$ \\
\hline $\begin{array}{l}\text { A comparatively lesser housing density interspaced with } \\
\text { ample greenery gives the very first rural look to these } \\
\text { rurban areas. }\end{array}$ & \\
\hline $\begin{array}{l}\text { Working member in most of the families are the males, } \\
\text { who either commutes or migrates to other cities for service, } \\
\text { trade and business, or for construction labour works. They } \\
\text { leave the dependent and poor family members back at } \\
\text { home; which is generally not the way urbanism is } \\
\text { perceived. }\end{array}$ & \\
\hline $\begin{array}{l}\text { Many local residents prefer giving away their unproductive } \\
\text { agriculture lands in lieu of liquid money to outsiders who } \\
\text { migrate in these rurban areas and start their living; but } \\
\text { people in urban areas will fight for retaining ownership of } \\
\text { every parcel of land. }\end{array}$ & \\
\hline $\begin{array}{l}\text { This marks the inflow of a new section of demography with } \\
\text { whom the local residents fail to match social class; hence } \\
\text { socialization, interaction, adaptation and adjustment seem } \\
\text { difficult on both ends; on the other hand, interaction in } \\
\text { urban society are limited within neighbourhoods and } \\
\text { polarized. }\end{array}$ & \\
\hline
\end{tabular}




\begin{abstract}
Not only is there a class segregation with local and migrant residents, but also within local residents themselves there seems to be two classes existing; the families engaged in trade and business or other service economy, and the families serving as the construction labour pool. The former is identified as comparatively richer than the latter in terms of livelihood earning and living status.

Also this former richer category opts for maintaining their town's status as census towns in order to refrain from any tax payments that levies automatically with attaining a municipal status. On the other hand, the latter category of people do not mind paying taxes, and look forward to a municipal body who can provide them with basic urban amenities like drinking water, adequate sanitation facilities, electricity, proper solid waste management, etc.
\end{abstract}

The rurban society rarely has a chance to avail public transport as there is hardly any available; and many of them cannot afford private motorized vehicles. Therefore walking, bicycle and at the most motorcycle are the only means. In contrary, one of the very image of urbanism is, fastest access to places using transit-oriented transport or owning a private vehicle.

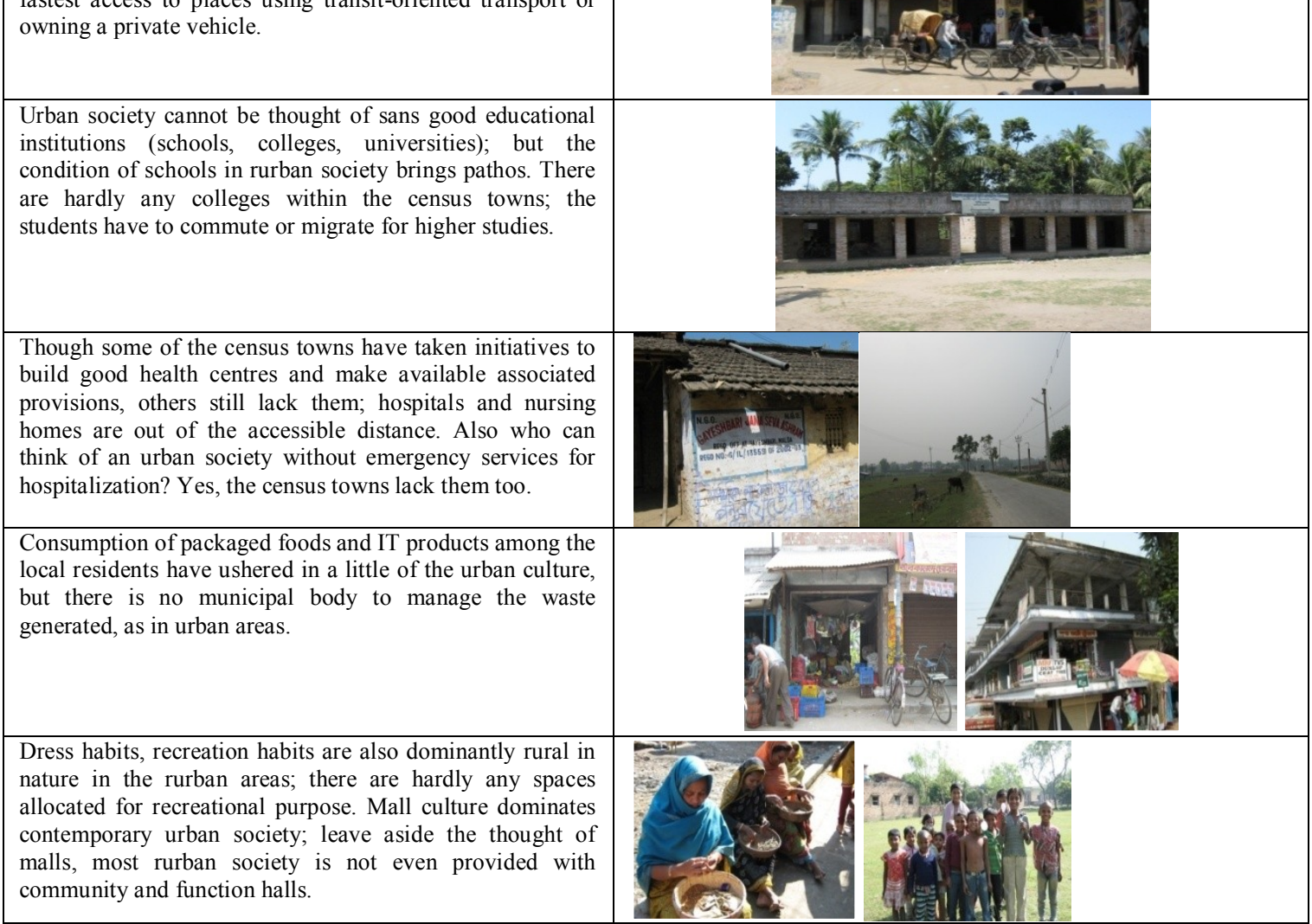

\title{
4.2. The Contradiction
}

Urbanization, as a change is obviously a long-term process, but there are cases where census towns have remained as census towns without any "municipalisation" [7] for more than ten years; even in such cases the socio-cultural attributes are as rural as it was ten years back. What is the factor of hindrance that is obstructing a rurban society to transform into an urban is worth pursuing. Or it may be the fact, that like we have a conventional notion of urbanism, the current way of life in rurban areas just adds on to the notion, without making any attempts to nurture and develop them with provision of basic urban amenities.

The observations on case studies of the rurban society in West Bengal can be generalized for the overall rurban space in India. These observations not only spell out the new urbanism dimensions in rurban society, but also impose the scope and importance of society or community development in urban planning policies in India. It can be well related in this context that, had the socio-cultural transformation come along with economic transformation, the rurban society would not had to experience issues in social interaction, access to basic urban amenities and better living. 


\section{The Rurban society and its challenges}

The rurban society in India faces challenges not only in the areas of improper governance and lack of existing urban policies, but also in terms of lack of social development policies in mainstreaming betterment of a society during the course of urbanization. The evolving and unattended rurban society may face the following challenges in near future:

- Increased conversion of agricultural land to non-agricultural uses, followed by outmigration of population from small and medium towns to Tier I, II towns or large cities.

- Subsequent in-migration from neighbouring urban areas making social adjustment and interaction more complex.

- Increased pressure on land resource, basic amenities and infrastructure facilities, with rising population density in rurban areas.

- Huge inflow of organized manufacturing activities in rurban areas absorbing rural non-farm labours, but posing a threat to the environment.

- Increased contribution of tertiary sector activities, leading to growth of a distinct middle income business class.

- Rising insecurity among local inhabitants regarding different socio-economic and cultural background of the immigrants; thereby creating a social divide.

- Failure of rural governing bodies to meet the needs of growing population and address their issues, which are very similar to those in larger towns and cities.

- Non-prioritization of development schemes by local governing bodies resulting in lack of basic services provision.

- Illegal and haphazard construction of residential buildings and commercial complexes, not following any buildings byelaws and regulations; such byelaws rarely exist in these towns. This in turn poses threats of evacuation to residents in the long run.

- Lack of an integrated social development policy and urban plan policy exclusively dedicated towards betterment of the rurban society.

All the challenges raise concern and need for acknowledgement and inclusion of the evolving rurban society, to bring them at par with what is understood as the urban society in India.

\section{Conclusion}

To mainstream social development policies in urban plan policies for rurban areas, the present study upholds some new facets of urbanism in rurban society to carry forward their development concerns in the eyes of social and urban policy planners. The study initiates a new beginning by unfolding some real life experiences of a growing potential society in India. Documentation of the experiences clearly spells out the issues that an economically progressive but socio-culturally stagnating society evidences during the course of urbanization. Though the case studies limit to one state, but they are appropriately representative of the whole country. The specifications and generalizations on rurban society and its new urbanism drawn in the paper, may possibly attract attention of strategic and state-specific policy makers, for incorporation of the target group in planning and development policies. The paper concludes to stir a thought among the readers, and expand scope for further research on, nurturing and developing the rurban society in India with necessary policy recommendations.

\section{Acknowledgements}

The author takes this opportunity to acknowledge the financial and technical support provided by the Director General of Centre for Good Governance, Hyderabad, India. I would like to extend my thanks to all the people whom I have interacted on field for information gathering and experience sharing.

\section{References}

[1] Census Publications, Town Directory, Office of the Registrar General and Census Commissioner, New Delhi, India, $2011,2001$.

[2] A. Kundu, Method in Madness: Urban Data from 2011 Census, Economic and Political Weekly, XLVI(40), 2011, 13-16.

[3] K.C. Pradhan, Unacknowledged Urbanisation: The New Census Towns of India, Urban Working Paper 2, Centre for Policy Research, New Delhi, 2012.

[4] N. Kleniewski, Cities And Society (Cornwall, UK: Blackwell Publishing, 2005)

[5] S. Chatterjee, The Rurbanized India, Yet Not 'Urban'- How Do Definitions and Policies Matter?, Proc. Conf. on International Symposium on Society economics and Urban Studies, Bali, Indonesia, 2014, 286-293.

[6] E. Ghani, A.G. Goswami, and W.R. Kerr, Is India's Manufacturing Sector Moving AwayFrom Cities?, Working Paper No. 12-090, Harvard Business School, Boston, 2012.

[7] G. Samanta, In Between Rural and Urban: Challenges for Governance of Non-recognized Urban Territories in West Bengal, West Bengal Geo-Spatial Issues, University of Burdwan, West Bengal, 2012, 44-57. 